\title{
Promoting Adolescent Mental Health Education through Art
}

\author{
Katie Chilton, MD
}

$\mathbf{P}$

atient decision aids are informative tools that educate patients about health conditions and promote shared decision-making between patient and provider. They have been shown to improve patient knowledge, reduce decisional conflict, and encourage patients to take an active role in their care. ${ }^{1}$ When made available in medical offices and public spaces, patient decision aids such as booklets, posters, videos, or other interactive tools can supply accurate, accessible information well beyond the reach of the specialist's clinic.

I created "Depression: A Deadly Predator" to provide adolescents with psychoeducation on depression. I designed this patient decision aid in a colorful, engaging format to appeal to a young population, believing that in order to have an impact, the reader must first want to listen. Cartoon comics like this can more broadly provide quality health information than can an individual physician, and in a way with which young people easily connect.

According to the World Health Organization, depression is now the leading cause of disability worldwide with over 300 million people affected. ${ }^{2}$ Although psychiatrists specialize in treating mental disorders, the majority of mental health issues are often tasked to primary care physicians (PCPS). One study shows that two-thirds or more of patients with depression receive their treatment in the general medical setting, ${ }^{3}$ and PCPs identify approximately onethird of their patients as mental health patients. ${ }^{4}$ One major reason for this is that the need for mental healthcare far outweighs the number of available psychiatrists, especially in rural and underserved areas. A recent study reported that about two-thirds of PCPs could not obtain outpatient mental health services for their patients. ${ }^{5}$ Lack of services can lead to missed detection and under treatment of mental illness. ${ }^{6}$ Mental health outreach is thus in high demand but limited by geography and availability of specialist practitioners. Patient decision aids may help surmount these barriers.

Only about half of teenagers experiencing a depressive episode contact someone in the 
healthcare sector. ${ }^{7}$ Although barriers to seeking care are multifactorial, a major one is a desire to appear "normal," leading patients to minimize symptoms to themselves and others. ${ }^{8}$ Even if a depressed teen seeks medical help, information provided in the form of a text-heavy office brochure is likely to be ignored or thrown away. Teenagers today are overburdened with information,
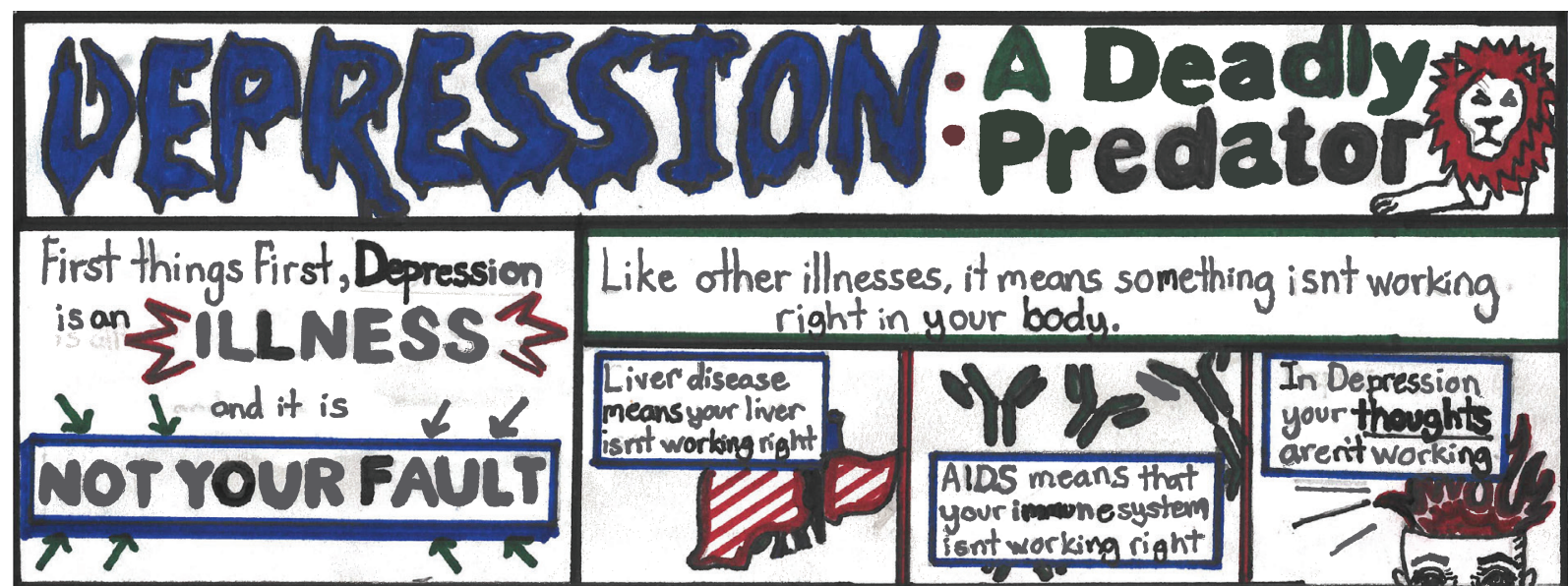

Like other illnesses, it means something isnt working right in your body.
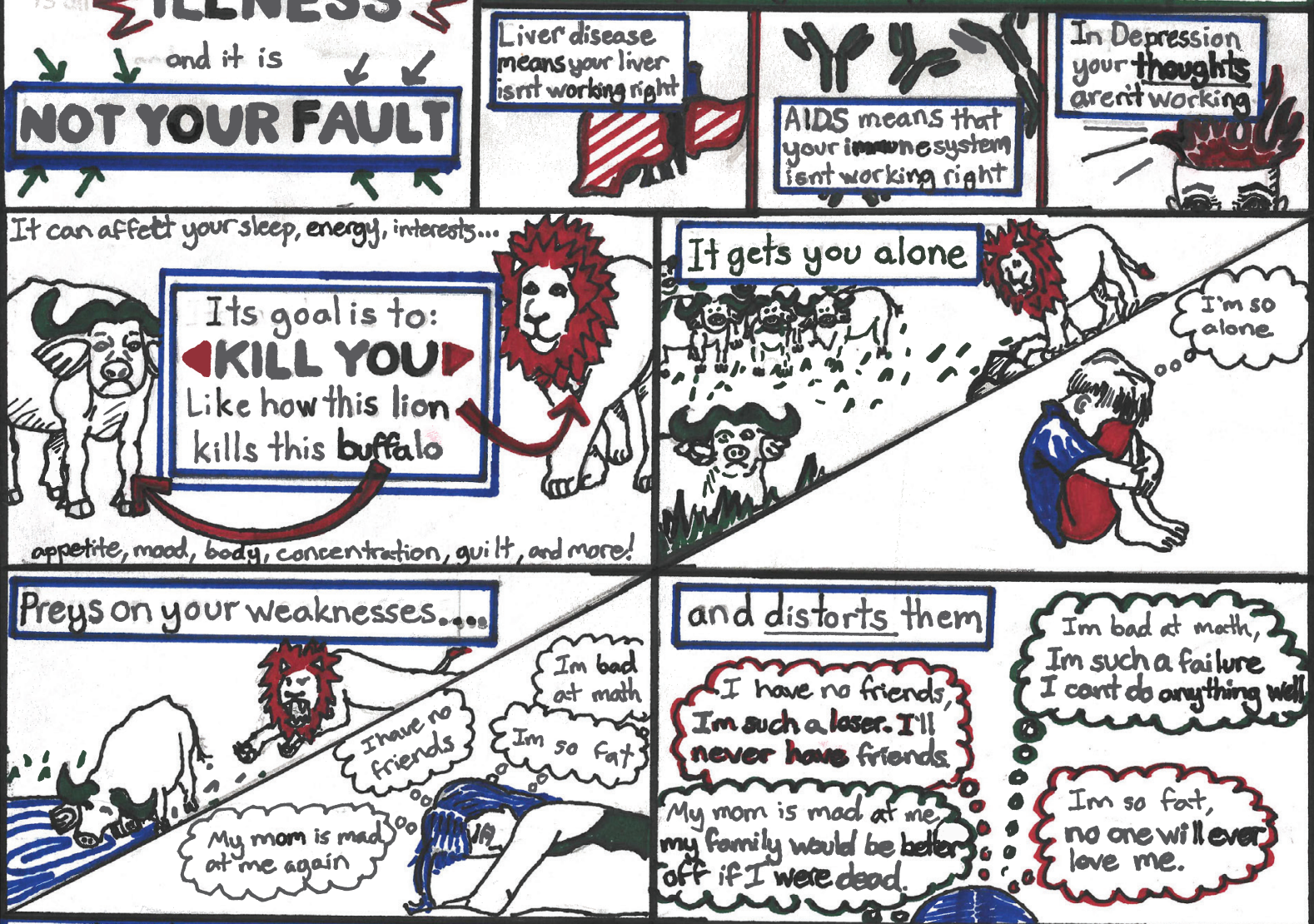

These thoughts may contain a "kernel of truth"'?

i.e. you failed a test or gained weight.
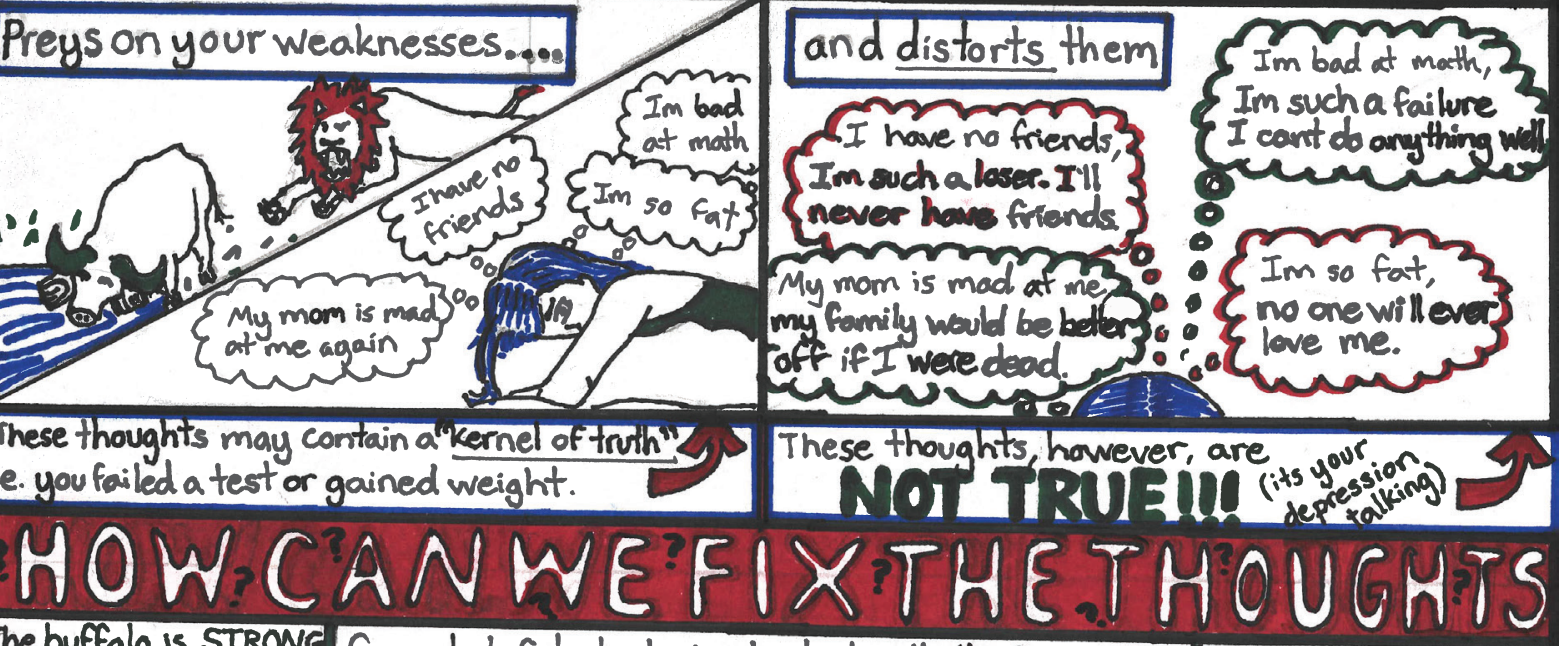

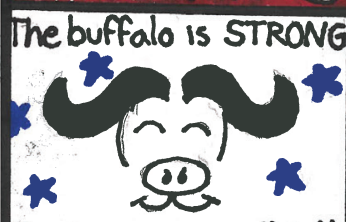

You are not your thaight and you CAN learn to control them.

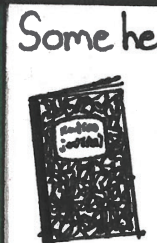

Write them down!

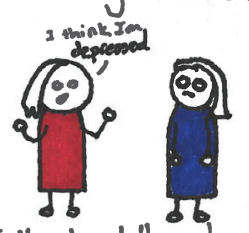

Talk about them honestly with friends or a therapist! yourself! meds!

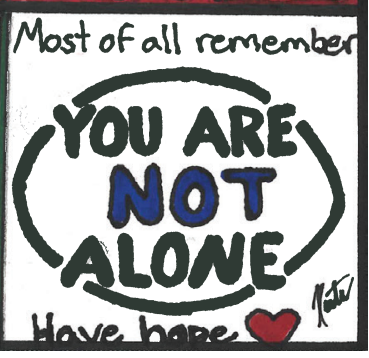


spending an average of nine hours a day consuming media, ${ }^{9}$ and are less receptive to information requiring sustained attention. This suggests that, in addition to the existing barriers to seeking care, professional and quality medical information has to compete for the attention of young patients' oversaturated minds.

An effective modern patient decision aid needs to be not only accurate but also easy to understand, entertaining, and available to be widely disseminated, such as on the internet. When creating this comic, I tried to encompass all of these qualities. I aimed to make it eye-catching and easy to access yet accurate. I avoided the sensationalism seen in internet blogs and, on the other end of the spectrum, avoided the inaccessibility of densely written medical texts. Mental health does not discriminate, and the hundreds of millions of patients suffering from depression represent all demographics, levels of medical literacy, and socioeconomic backgrounds. Approachable patient aids are also particularly crucial with depression, because it is the nature of the disease to foster feelings of inadequacy; therefore people believe that they do not deserve help.

We need to ensure that patients are receiving engaging information that can help them gain better control over their health and their lives. I plan to draw a series of these patient aids to introduce often-misunderstood conditions such as anxiety, psychosomatic disorders, and borderline personality disorder. I hope that the aids serve to start constructive conversations and possibly encourage people to ask for help. The path toward mental health is often a long and arduous one. There are those who cannot make this journey alone, and art is a great way to both connect with and inform these individuals.

\section{References}

1. O'Connor AM, Rostom A, Fiset $\mathrm{V}$, et al. Decision aids for patients facing health treatment or screening decisions: systematic review. BMJ. 1999;319(7212):731-734.

2. Depression: Key facts. World Health Organization. http://www.who.int/news-room/fact-sheets/detail/ depression. Published March 22, 2018. Accessed September 9, 2018.

3. Oxman TE, Dietrich AJ, Williams JW, Kroenke K. A three-component model for reengineering systems for the treatment of depression in primary care. Psychosomatics. 2002;43(6):441-450. doi:10.1176/appi.psy.43.6.441

4. Abed Faghri NM, Boisvert CM, Faghri S. Understanding the expanding role of primary care physicians (PCPs) to primary psychiatric care physicians (PPCPs): enhancing the assessment and treatment of psychiatric conditions. Ment Health Fam Med. 2010;7(1):17-25.

5. Cunningham PJ. Beyond parity: primary care physicians' perspectives on access to mental health care. Health Aff (Millwood). 2009;28(3):w490-501. doi:10.1377/hlthaff.28.3.w490

6. Vermani M, Marcus M, Katzman MA. Rates of detection of mood and anxiety disorders in primary care: a descriptive, cross-sectional study. Prim Care Companion CNS Disord. 2011;13(2):PCC.10m01013. doi:10.4088/PCC.10m01013

7. Ustün TB. Cross-national epidemiology of depression and gender.J Gend SpecifMed. 2000;3(2):54-58.

8. Wisdom JP, Clarke GN, Green CA. What teens want: barriers to seeking care for depression. Adm Policy Ment Health. 2006;33(2):133-145. doi:10.1007/ s10488-006-0036-4

9. Tsukayama H. Teens spend nearly nine hours every day consuming media. Washington Post. November 3, 2015. 